\title{
PREVALENCE OF MICROALBUMINURIA AND ITS ASSOCIATION WITH GLYCEMIC CONTROL IN TYPE 2 DIABETIC PATIENTS: A CROSS SECTIONAL STUDY AT KATHMANDU MEDICAL COLLEGE \\ Prabin Kumar Karki ${ }^{1}$, Santosh Timalsina ${ }^{2}$, Sanat Chalise ${ }^{3}$, Anita Yadav ${ }^{4}$, Ashish Kumar Bhattarai ${ }^{5}$ \\ ${ }^{1}$ Lecturer, Department of Physiology, Kathmandu Medical College \\ ${ }^{2}$ Assistant Professor, Department of Biochemistry, Chitwan Medical College \\ ${ }^{3}$ Assistant Professor, Department of Pathology, Kathmandu Medical College \\ ${ }^{4}$ Lecturer, Department of Biochemistry, Kathmandu Medical College \\ ${ }^{5}$ Lecturer, Department of Pharmacology, Kathmandu Medical College
}

Received: 15 Nov, 2018

Accepted: 20 Mar, 2019

Published: 31 Mar, 2019

Key words: Diabetes; HbA1c; Microalbuminuria.

*Correspondence to: Dr. Prabin Kumar Karki

Lecturer, Department of Physiology, Kathmandu Medical College, Duwakot

Email: prabinkaarki@gmail.com

\section{Citation}

Karki PK, Timalsina S, Chalise S, Yadav A, Bhattarai AK. Prevalence of microalbuminuria and its association with glycemic control in type 2 diabetic patients: a cross sectional study at Kathmandu Medical College. Journal of Chitwan Medical College. 2019; 9 (27): 2-7.

\section{ABSTRACT}

Background: Diabetes mellitus has become one of the biggest health problems of this era. The resultant microvascular and macrovascular complications add to significant amount of morbidity and mortality. Urine microalbumin is considered as an early marker for microvascular complications among diabetic patients. The aim of this study was to find out the prevalence of microalbuminuria among type 2 diabetic patients attending Kathmandu Medical College and its relation with glycemic control, age, sex, duration of diabetes.

Methods: A total of 208 previously diagnosed type 2 diabetic patients attending medical outpatient department of Kathmandu Medical College, Sinamangal were included in the study over a period of 1 year (October 2017 - September 2018). Fasting and 2-hour postprandial venous blood for blood glucose and $\mathrm{HbA} 1 \mathrm{c}$ measurement and early morning urine sample (after overnight fast) was collected for detection of microalbuminuria. Statistical analysis was done using SPSS version 23.

Results: The prevalence of microalbuminuria among the study population (mean age: $54.22 \pm 11.76$ years, mean HbA1c: $7.62 \pm 1.53 \%$ ) was $42.8 \%$. Microalbuminuria had significant correlation with $\mathrm{HbA} 1 \mathrm{c}$ and duration of diabetes $(p<0.001)$, but not with age, sex and type of medication. There was positive correlation between urine microalbumin and fasting and post-prandial blood glucose.

Conclusions: Our present study found high prevalence of microalbuminuria among diabetic patients with poor glycemic control. It is suggested that tighter glycemic control with regular urine microalbumin testing should be integral part of diabetic management plan to prevent long term complications such as diabetic nephropathy

\section{INTRODUCTION}

Diabetes mellitus is a metabolic disorder characterized by hyperglycemia resulting from variable degree of insulin resistance, impaired insulin secretion or both. ${ }^{1,2}$ The global prevalence of diabetes mellitus is on a steady rise, with the world population with this condition projected to reach 592 million by $2035 .^{3}$ In Nepal, the pooled prevalence of type 2 diabetes mellitus (T2DM) has been reported to be $8.4 \%$, the variability being seen in rural and urban population ${ }^{4}$, and is bound to increase in the coming years, driven by rapid urbanization, shift towards sedentary lifestyles and nutrition transition leading to overweight and obesity. Complications from diabetes mellitus can be divided into microvascular (such as retinopathy, neuropathy, nephropathy) and macrovascular (such as acute myocardial infarction, peripheral vascular disease, stroke) varieties that result in significant morbidity and mortality, adding 
to the burden of disease. Diabetic nephropathy, as defined as diabetes with albuminuria or impaired glomerular filtration rate, or both is one of the frequent microvascular complications with variable prevalence $(2.2 \%-14.2 \%)$ in different population. ${ }^{5,6}$ Microalbuminuria is considered as an early marker of diabetic nephropathy, with higher levels of urinary albumin representing a generalized vascular damage rather than renal microvascular injury alone. ${ }^{7}$ In recent years, the incidence of end stagerenal disease (ESRD) has increased drastically that has been attributed to increased incidence of diabetes mellitus in the general population. ${ }^{8}$ Diabetic nephropathy has been reported as one of the leading etiologies of ESRD in Nepal. ${ }^{9}$

Glycosylated hemoglobin ( $\mathrm{HbA} 1 \mathrm{c}$ ) is used as a marker of blood glucose controlin the diabetic patients.It determines average glycemic control over a period of 8-12 weeks and its higher values correlate with the development of microvascular complications in the diabetic patients. ${ }^{10}$ The Diabetes Control and Complications Trial (DCCT) and United Kingdom Prospective Diabetic Study (UKPDS) highlighted the fact that careful monitoring and control of glycemia $(\mathrm{HbA} 1 \mathrm{c}<7.0 \%)$ in patients with T2DM decreased the possibility of developing microalbuminuria by $34 \%$ and therefore, maintaining optimal $\mathrm{HbA} 1 \mathrm{c}$ has been advised for all diabetic patients to prevent such complications. ${ }^{11,12}$

With the rise in the patients with T2DM in Nepal and the well-known importance of early diagnosis, treatment and prevention of microalbuminuria in this population, this study was aimed at describing the prevalence of microalbuminuria in T2DM patients, the patient characteristics and evaluating the relationship between microalbuminuria and glycemic control.

\section{METHODS}

A cross-sectional study was conducted from October 2017 to September 2018. Ethical clearance was obtained from the Institutional Review Committee (IRC) of Kathmandu Medical College(Ref No. 02082017). The study group comprised of 208 previously diagnosed type 2 diabetic patients (duration of diabetes $>6$ months) attending medical outpatient department of Kathmandu Medical
College, Sinamangal. Exclusion criteria were patients with newly diagnosed diabetes mellitus, patients with other causes of proteinuria, hematuria and renal failure, recent history of urinary tract infection and presence of any self-reported acute illness or fever after taking detailed history and observing previous medical records.

After taking written consent from the research participants during their outpatient visits, an interviewer-administered questionnaire was completed that included socio-demographic data and detailed medical history including the list of current medication. Two blood samples $(5 \mathrm{ml})$ weredrawn by venipuncture under aseptic conditions by trained laboratory personnel. The first sample was collected in the morning after overnight fasting (minimum 8 hours) for estimation of serum fasting blood glucose (FBG) and whole-blood HbA1c whereas the second blood sample was drawn $2 \mathrm{~h}$ after an average meal by the patients for estimation of serum postprandial blood glucose (PPBG). A single spot urine sample was collected in the early morning after overnight fasting. Blood glucose was determined by Selectra Pro $\mathrm{M}$ analyzer (EliTech Clinical Systems) using enzymatic colorimetric method (GOD/POD/ PAP method).

$\mathrm{HbA1c}$ (Glycated hemoglobin) was measured using chromatographic technique by D-10TM Hemoglobin analyzer(Bio-Rad Laboratories, Inc.). Based on HbA1c values, the glycemic control was categorized into: a) good control ( $\leq 7.0 \%)$, b) fair control (7.01 - 8.20 $\%)$,and c) poor control (> $8.20 \%)$.Urinary albumin was measured by point-of-care NycocardTM urinaryalbumin test.In controlled laboratory testing, a precision of $<10 \%$ expressed by the coefficient of variation (CV) is usually achieved for the test. A diagnosis of microalbuminuria was made if urinary albumin was $\geq 20 \mathrm{mg} / \mathrm{L}$ up to $200 \mathrm{mg} / \mathrm{L}$. Values above $200 \mathrm{mg} / \mathrm{L}$ were classified as clinical albuminuria.

Data was collected, compiled and analyzed by using Statistical Package of Social Science (SPSS) software version 23. The data were expressed as mean \pm SD or median (minimum-maximum) as appropriate. The mean and median comparisons of different variables between no-microalbuminuria and microalbuminuria-present groups was done by student's t-test and Mann-Whitney U-test respectively. The difference in proportions was 
analyzed by chi-square test. The association between $\mathrm{HbA} 1 \mathrm{c}$ and microalbuminuria was determined by Spearman's rank correlation coefficient. P-value of < 0.05 was considered to be statisticallysignificant.

\section{RESULTS}

A total of 208 diabetic patients (mean age: $54.22 \pm$ 11.76 years, age ranging from $29-84$ years) were included in the study. There were 97 males (46.6 \%) and 111 females (53.4\%).The median duration of diabetes was 5 years (Range: $0.5-21$ years). $81.3 \%$ of the patients were using oral hypoglycemic agents (OHAs), and the remaining $18.8 \%$ were using insulin.

The mean $\mathrm{HbA} 1 \mathrm{c}$ of the study population was 7.62 $\pm 1.53 \%$. Sub-dividing the study group based on glycemic control, approximately only one-third of the patients (36.5\%) had good glycemic control [Table 1].

Table 1: Frequency and mean $\mathrm{HbA1c}(\%)$ of the patients based on glycemic control status

\begin{tabular}{|l|l|l|l|}
\hline Glycemic control group & No. of patients & Percentage (\%) & HbA1c (mean \pm SD)\% \\
\hline Good control & 76 & $36.5 \%$ & $6.18 \pm 0.51 \%$ \\
\hline Fair control & 82 & $39.4 \%$ & $7.59 \pm 0.35 \%$ \\
\hline Poor control & 50 & $24.0 \%$ & $9.85 \pm 1.04 \%$ \\
\hline Total & 208 & $100.0 \%$ & \\
\hline
\end{tabular}

In the study population, $89 / 208$ patients $(42.8$ albuminuria i.e. above the range for definition of $\%)$ had microalbuminuria and $55.8 \%$ didn't microalbuminuria and these were excluded from have the condition. 3 of the patients had clinical further analysis[Table 2].

Table 2: Frequency of patients based on microalbuminuria status

\begin{tabular}{|l|l|l|}
\hline \multicolumn{1}{|c|}{ Status } & No. of patients & Percentage (\%) \\
\hline No microalbuminuria & 116 & $55.8 \%$ \\
\hline Microalbuminuria & 89 & $42.8 \%$ \\
\hline Clinical albuminuria & 3 & $1.4 \%$ \\
\hline
\end{tabular}

The diabetic patients who had microalbuminuria had significantly longer duration of disease and higher mean $\mathrm{HbA1c}$ levels compared to the patients without microalbuminuria. The two groups were not different in age, sex and medication use distribution [Table 3].

Table 3: Demographic variables and HbA1c of the patients expressed as mean \pm SD or frequency or median (minimum- maximum) as appropriate based on microalbuminuria status

\begin{tabular}{|c|c|c|c|}
\hline \multirow[b]{2}{*}{ Variables } & \multicolumn{2}{|c|}{ Microalbuminuria status } & \multirow[b]{2}{*}{ Chi-Square } \\
\hline & $\begin{array}{l}\text { No microalbuminuria } \\
(n=116)\end{array}$ & $\begin{array}{l}\text { Microalbuminuria } \quad \text { present } \\
(n=89)\end{array}$ & \\
\hline Age (years) & $53.07 \pm 12.06$ & $56.16 \pm 11.07$ & 0.06 \\
\hline Sex (Male/Female) & $52 / 64$ & $43 / 46$ & 0.62 \\
\hline $\begin{array}{l}\text { Medication use (OHA/ } \\
\text { Insulin) }\end{array}$ & $99 / 17$ & $67 / 22$ & 0.07 \\
\hline $\begin{array}{l}\text { Duration of diabetes } \\
\text { (years) }\end{array}$ & $4.00(0.50-20.00)$ & $8.00(0.50-21.00)$ & $<0.001$ \\
\hline HbA1c (\%) & $6.93 \pm 0.94$ & $8.45 \pm 1.65$ & $<0.001$ \\
\hline
\end{tabular}


Glycemic control (expressed as $\mathrm{HbA} 1 \mathrm{c}$ ) was positively correlated with microalbuminuria status (Spearman's rho $=0.478, \mathrm{P}<0.001$ ). On post-hoc contingency table analysis (using adjusted residual method), the proportion of patients with microalbuminuria was significantly higher in poor glycemic control group compared to good glycemic control group (46.1\% vs. $18.1 \%, \mathrm{P}<0.001)$. Conversely, the good glycemic control group had a far greater proportion of patients without microalbuminuria compared to poor glycemic control group (50.9 \% vs. $6.0 \%$, P< 0.001).

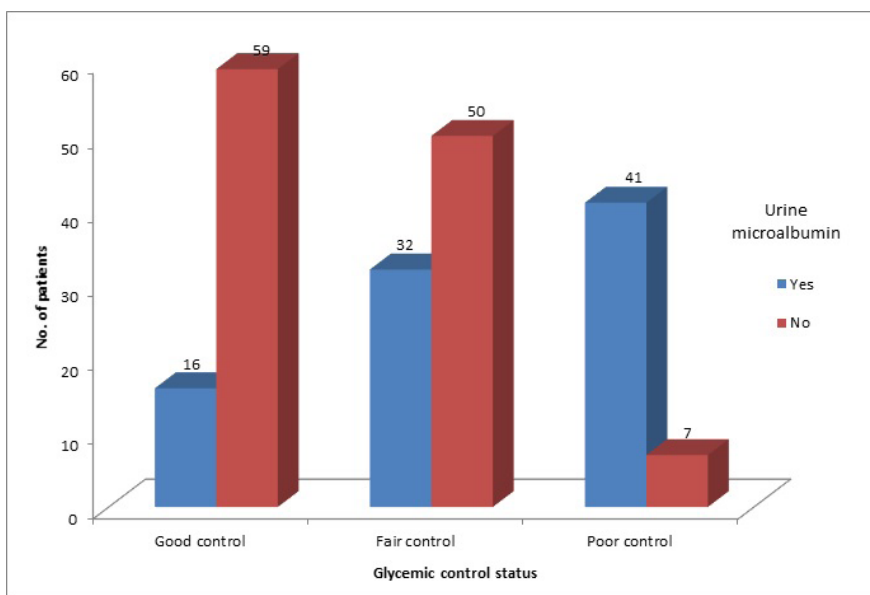

Fig 1: Bar diagram showing the distribution of microalbuminuria in relation to glycemic control ( $\mathrm{n}$ = 205)

The urine microalbumin had significant positive correlations with both fasting and post-prandial blood glucose (Pearson's $r=0.461$ and 0.458 respectively, $\mathrm{P}<0.001)$.

\section{DISCUSSION}

Diabetes mellitus has a long natural history, because of which there is a high prevalence of micro- and macrovascular complications in the patients with this condition. These have added burden to the patients, health care providers and the national health system.It's an unarguable fact that the risks of complications in patients with diabetes mellitus are significantly reduced by improving the glycemic control (which is done by targeting $\mathrm{HbAlc}$ in the patient to remain in the desired range). ${ }^{13}$ The present study shows that only one-third of the patients had good glycemic control which is alarming, increasing the susceptibility of the patients to develop diabetic complications.

In the present study, 208 patients were studied and the overall prevalence of microalbuminuria was found to be $42.8 \%$. A study conducted by Sigdel et $\mathrm{al}^{14}$ in Pokhara(45.5\%) and and Khadka B et $\mathrm{al}^{15}$ in Rupandehi (46.5\%) reported similar prevalence Similarly, Ambayiramet al. $^{16}$ also reported comparable prevalence of microalbuminuria with $41.5 \%$ in Chidambaram, India. The prevalence, however, have differed significantly in different studies (such as a lower prevalence of $14.2 \%$ in a study by Ardekani et $\mathrm{al}^{6}$ ). This variation may be due to different factors like differences in the study population, techniques used for urine collection, time and amount of urine collected, differences in methods of measuring microalbuminuria, criteria for defining microalbuminuria etc. The mean $\mathrm{HbA} 1 \mathrm{c}$ of the study population was $7.62 \pm 1.53 \% .24 \%$ had poor glycemic control. The prevalence of microalbuminuria was significantly higher in poor glycemic control group compared to good glycemic control group, strongly supporting findings from previous studies. ${ }^{17,18}$ Several studies have revealed age, sex, duration of diabetes, body mass index and poor glycemic control as risk factors for development of microalbuminuria., ${ }^{7,18}$ Our study showed that patients with microalbuminuria had longer duration of disease and higher $\mathrm{HbA1c}$ levels. The presence of microalbuminuria was not affected by age, sex and type of medication used. ${ }^{6,14}$ Therefore, it can be concluded from our study that good glycemic control and early diagnosis of diabetes and institution of therapy are the two important predictors of development of microalbuminuria in these patients.

In our study, we found significant correlation between $\mathrm{HbA} 1 \mathrm{c}$ and microalbuminuria as supported by earlier studies. ${ }^{7,17,18}$ However, there are studies that did not show significant association between these two. ${ }^{19}$ These differences in findings may be due to limited sample size, less time allocation for the duration of study or variationin stage of the disease in study population.The urine microalbumin had significant positive correlations with both fasting and post-prandial blood glucose, supporting the outcome of previously conducted studies. ${ }^{7,18}$ This highlights the fact that diabetic patients should have tighter control of blood glucose to minimize microvascular complications.

One important aspect to consider is the hospitalbased nature of our study that has introduced selection bias and therefore, might not be true 
representative of the diabetic population. There is scope of further study including important variables among larger diabetic population.

\section{CONCLUSION}

There is a high prevalence of microalbuminuria in patients with type 2 diabetes mellitus, which is associated with longer duration of disease and poor glycemic control.Regular testing of $\mathrm{HbA1c}$ and urine microalbumin should be an integral part of diabetic patient management (particularly for the patients with long duration of disease) to prevent and earlydiagnose renal complications associated with the condition.

\section{REFERENCES}

1. Defronzo RA. Pathogenesis of type 2 diabetes mellitus:metabolic and molecular implications for identifying diabetes genes Diabetes Rev. 1997;5:177-269.

2. ADA. Diagnosis and classification of diabetes mellitus. Diabetes care 2014 Jan;Suppl 1:S81-90. doi: $10.2337 /$ dc14-S081.

3. Wild S, Roglic G, Green A, Sicree R, King H. Global prevalence of diabetes: estimates for the year 2000 and projections for 2030. Diabetes care. 2004;27(5):1047-53. PMID: 15111519.

4. Gyawali B, Sharma R, Neupane D, Mishra SR, van Teijlingen E, Kallestrup P. Prevalence of type 2 diabetes in Nepal: a systematic review and metaanalysis from 2000 to 2014. Global Health Action. 2015;8:29088. doi:10.3402/gha.v8.29088

5. de Boer IH, RueTC, Hall YN, Heagerty PJ, Weiss NS, Himmelfarb J Temporal trends in the prevalence of diabetic kidney disease in the United States. JAMA. 2011;305(24): 2532-9. doi: 10.1001/ jama.2011.861.

6. Afkhami-Ardekani M, Modarresi $M$, Amirchaghmaghi E, Prevalence of microalbuminuria and its risk factors in type 2 diabetic patients. Indian J Nephrol.,2008; 18(3): 112-7.doi: 10.4103/0971-4065.43690.

7. Varghese A, Deepa R, Rema M, Mohan V. Prevalence of microalbuminuria in type 2 diabetes mellitus at a diabetes centre in southern India. Postgrad Med J. 2001;77:399-402. doi:10.1136/ pmj.77.908.399

8. Raij L. Recommendations for the management of special populations: Renal disease in diabetes. Am J Hypertens. 2003;16:46S-9S. doi:10.1016/j. amjhyper.2003.07.006

9. Bartaula B, Subedi M, Kumar M et al. Spectrum of complications in chronic kidney disease patients undergoing maintenance hemodialysis: An experience of a tertiary care center in Nepal. Saudi J Kidney Dis Transpl. 2019; 30(1): p. 208214. PMID: 30804283.

10. Jesudason DR, Dunstan K, Leong D, Wittert GA. Macrovascular Risk and Diagnostic Criteria for Type 2 Diabetes. Diabetes Care 2003; 26: 485-90. PMID: 12547886.

11. Fioretto P, Bruseghin M, Berto I, Gallina P, Manzato $E$, Mussap M. Renal protection in diabetes, role of glycemic control. J Am Soc Nephrol 2006; 17: 86-9. doi:10.1681/ASN.2005121343.

12. Diabetes control and complication trial research group. The relationship of glycemic exposure $(\mathrm{HbA1C})$ to the risk of development and progression of retinopathy in the diabetes control and complication trial. Diabetes. 1995;44:96883.PMID:7622004.

13. Hirsch I.B. Glycemic Variability and Diabetes Complications: Does It Matter? Of Course It Does! .Diabetes Care, 2015. 38(8): p. 1610-4. doi: 10.2337/dc14-2898.

14. Sigdel M, Rajbhandari N, Basnet S, Nagila A, Basnet $P$, Tamrakar BK. Microalbuminuria among type 2 diabetes mellitus patients in Pokhara, Nepal. Nepal Med Coll J 2008;10(4):242-5. PMID: 19558062.

15. Khadka B, Tiwari ML, Timalsina B, Risal P, Gupta $S$, Acharya D. Prevalence and factors associated 
with microalbuminuria among type 2 diabetic patients: A hospital based study. J Nepal Med Assoc. 2018 Jan-Feb;56(209):516-21. PMID: 30058635 .

16.Ambayiram AV, Kalyani P, Felix AJW, Govindarajan PK. Prevalence of microalbuminuria among type II diabetic mellitus patients in urban Chidambaram. Saudi J Med. 2016;1(3):57-62. doi: 10.21276/sjm.2016.1.3.1

17. Goyal B, Goyal J, Sinha M, Fiza B, Sharma P, Bhandari $S$ et al. Association of glycosylated hemoglobin with microalbuminuria in patients with type 2 diabetes mellitus. International
Journal of biotechnology and biochemistry 2017;13(4):311-23.

18. Sheikh SA, Baig JA, Iqbal T, Kazmi T, Baig M, Husain SS. Prevalence of microalbuminuria with relation to glycemic control in type 2 diabetic patients in Karachi. J Ayub Med Coll 2009;21(3);83-6. PMID: 20929021.

19. Maharjan BR, Bhandary S, Risal P, Sedhain A, Shakya PR, Gautam M. Microalbuminuria and macroalbuminuria in type 2 diabetes. J Nepal Health Res Counc 2010 Oct;8(17):110-15. PMID: 21876575. 